\title{
Substance abuse treatment, what do we know?
}

\section{An economist's perspective}

\section{Introduction}

The take-off of substance abuse treatment programs occurred during the opioid epidemic of the 1960 s when the United States Government released substantial funds to these programs (by 1996 it was spending $\$ 2.8$ billion in illicit drugs treatment programs alone [18]). Since then state governments and private sources have also contributed to the funding of these programs. The availability of research money and data drew the attention of academics and the literature on the subject mounted. Forty years later the number of studies on substance abuse treatment is so large that it is hard to survey the literature. My aim is therefore not to survey the literature extensively but to categorize and summarize the principal findings, ${ }^{1}$ from the point of view of an economist. The term "substance abuse treatment" is used here to refer to alcohol and drug treatment in general; smoking is not included in this survey.

The literature on treating substance abuse has focused on four questions: (a) Is treatment effective? (b) Are all programs equally effective? (c) Why do programs differ in their effectiveness? (d) Which treat-

${ }^{1}$ References were selected from Medline, ABI-INFORM, ECONLIT and survey papers were also used as a source. Articles were also selected from the table of contents of volumens of Addiction and Journal of Studies on Alcohol. Some of the keywords used in the search were: substance abuse; drug abuse; alcohol abuse; effectiveness; cost-effectiveness; acamprosate; MATCH; self-report, economic evaluation, treatment programs. ments are more cost effective ${ }^{2}$ It may come as a surprise that these four questions have been debated for almost 40 years. The reason lies in a range of methodological issues that restrict the interpretation and generalization of results from previous research. The following section addresses the three questions above regarding outcome assessment, and the subsequent section surveys the studies on costeffectiveness. I then briefly discuss the main methodological issues involved in the outcome assessment evaluations and issues related to cost evaluations.

\section{Outcome assessment evaluation}

\section{Is treatment effective?}

To address the question "is treatment effective?" one must define effectiveness. This is not straightforward. McLlelan et al. [45] point out that "effectiveness" does not necessarily have a common definition for everyone but instead depends on the expectations of each agent involved in the treatment process or treatment financing (e.g., patients, society, judicial system, insurance companies): They difine three objectives that represent the spectrum of these agents' expectations about treat-

${ }^{2}$ For the interested reader, there is an important economic literature on the theories of addiction. This paper deals with the treatment of substance abuse and although different theories may lead to different treatment approaches and philosophies, in this paper I only compare autcomes and do not discuss the theories that may support them. ment outcome: (a) reducing alcohol and/ or drug use, (b) improving personal and social functioning, and (c) improving public health. McLlelan et al. [45] review the literature and conclude that in spite of frequent methodological inaccuracies the evidence largely indicates that treatment is effective in each of these aspects.

\section{Are all programs equally effective?}

The next obvious question, once it is known that treatment is indeed effective, is whether all programs are equal in their effectiveness. The attempts to answer this important question probably started with Emrick (1975) who argued that the literature did not sustain evidence that programs were different in their performance. In contrast, the more recent literature includes many references to large differences in effectiveness of substance abuse treatment programs even within the same treatment modality (e.g., $[1,4,7,43$, 45]). The methodological sophistication of the more recent studies lead us to conclude that not all programs are equally effective.

As an illustration, let me describe McLellan et al. [43] and Ackerberg et al. [1]. McLellan et al. [43] restrict their study to four top private programs (two outpatient, two inpatient) having the same philosophy, same treatment goals, and no observable significant difference in their patient populations. These authors found significant differences both in the number and type of services provided to patients and in the programs' effectiveness. 
The authors stress that the differences are likely to be even larger among a more general pool of programs, in particular public programs, as funding for public programs may be very unstable. Ackerberg et al. [1] studied publicly funded programs for the outpatient treatment of alcoholic patients, controlling for patient characteristics and for unobservable heterogeneity that may lead to bias. One of their conclusion is that programs vary quite substantially in their effectiveness to reduce patients' alcohol consumption.

As the paper by Ackerberg et al. [1] reflects, restriction to a single modality is no guarantee of homogeneity. The Institute of Medicine [21] report when defining outpatient nonmethadone treatment programs states that they "display a great deal of heterogeneity in their treatment processes, philosophies, and staffing" as well as in their patient population. Another illustration of program heterogeneity and its sources is the evaluation by Ball and Ross [7] of six methadone treatment programs. Although methadone treatment is probably the most homogeneous treatment modality, the authors point out that "it has not been sufficiently recognized, however, that individual programs rather than an entire modality may well be the crucial unit of analyses when determining treatment effectiveness."

\section{Why do programs differ in effectiveness?}

The question "why do programs differ?" is fairly recent in the literature and will most likely characterize the next decade on substance abuse treatment research. It deals with opening what the literature has labeled the "black-box" and inquires about the "active ingredients" of treatment (e.g., $[7,15,43,44,48,49])$. "Black-box" factors that have been traditionally used to explain differences between programs include both patient characteristics and a number of treatment characteristics such as treatment duration, treatment intensity, and special services. Most studies based on the "black box" type of approach relied on the role of patient characteristics, such as less severe dependence, intact marriage, lower psychiatric symptoms, job, less family problems, and minimal criminal activ- ity $[1,4,6,36,45]$ as the main predictors of differences across programs. However, these characteristics are generally insufficient to explain the degree of heterogeneity between modalities and between programs within the same modality. Moos et al. [48], for example, in their sample of five residential programs concluded that social background accounted only for less than $2 \%$ of the variance in drinking outcomes.

Treatment duration is another factor that is usually found in traditional "blackbox" studies to account for differences between programs. The literature repeatedly refers to the "time effect": patients who undergo longer treatment do better on average $[7,21,33,36,45,48,58] .{ }^{3}$ Some of the studies that use time in treatment have not taken into account its potential endogeneity. Endogeneity is present if patients who dropout of treatment prematurely, for example, are harder to treat. This self-selection of patients into out-of-treatment would lead to overestimation of the effect of treatment duration on treatment outcomes. There are some exceptions where treatment duration is treated as an endogenous variable, for example, Ackerberg et al. [1] endogenize treatment duration within a structural model of the treatment process. ${ }^{4}$ French et al. [19] use first differences to eliminate error components that

\section{${ }^{3}$ There is a new trend analyzing the effects of "brief interventions" (BI) for alcoholics, and a number of studies claim its effectiveness rela- tive to longer treatment periods. Drummond [13], however, refutes this new literature main- ly on the basis of sample selection. Trent [59] reported shorter programs to be more effective than longer ones, but this study did not ran}

${ }^{4}$ Adhering to the "black-box" type of evaluation may be not only convenient but sufficient. The latter authors analyze the problem of allocating a fixed budget among a set of programs believed to follow roughly the same treatment philosophies and goals over time and patients. Their dynamic structural model of the treatment process can detect wide differences between programs regarding observable and unobservable characteristics of patients at admission, patients' progress through treatment, patients' completion criteria, and programs' capacity to hold patients until treatment completion. Joe et al. [29] also model treatment in a dynamic framework, but for their particular approach they need a truncated sample of patients in treatment for at least 3 months. are correlated with treatment duration, a technique that works only if strong parameter assumptions hold. Lu and McGuire [36] employ instrumental variables to eliminate the bias introduced when including treatment duration in their regressions.

Treatment duration is also often used as a proxy for services received, under the premise that longer stays should yield a higher exposure to treatment. Again, it is important to control for endogeneity if one wishes to draw conclusions regarding causal effects. Several studies report associations between better outcomes and the amount of services used. McLellan et al. [43] associated differences in outcomes between programs with type and quantity of treatment services. These authors concluded that programs directing more services to a particular area had better patient outcomes in that area, and that differences between programs were less accounted for by patient characteristics than by differences in the treatment programs. Examining randomized clinical trials, McLellan et al. [44] found evidence that providing additional services (e.g., medical, psychiatric, employment, family therapy) to the baseline methadone programs had a positive effect on outcomes. This finding is particularly important since the use of random clinical trials avoids at least in theory the endogeneity and selection problems that are likely to produce biases in estimations using field data. McLellan and coauthors [46] later showed that the introduction of case management doubles patients' likelihood of abstinence. ${ }^{5} \mathrm{Lu}$ and McGuire [36] used instrumental variables to control for the potential endogeneity of units of treatment received (and for treatment duration). They found a positive and significant effect of more units of treatment for moderate and heavy substance abusers, although these effects vanished once they controlled for interaction between duration and units of treatment.

Some studies concentrate more on treatment intensity rather than treatment duration as a better predictor of differ-

\footnotetext{
${ }^{5}$ Papers where treatment services such as participation in therapy sessions, Alcoholic Anonymous meetings, films, attendance to church, etc. and outcomes are associated but where no causation can be established include: Moos, Finney and Cronkite (1990) and Ball and Ross (1991).
} 
ences in outcomes. Finney et al. [15] review the 14 best studies comparing outpatient and inpatient programs and found that only seven observed significant differences in drinking-related outcomes between inpatient and outpatient programs. Of these seven studies five favored inpatient programs, which proved to be the most intensive. Walsh et al. [6o] randomized patients to three treatment modalities: regular AA meetings, AA meetings with 2 weeks of prior hospitalization, and client's choice of treatment. They found that the group with 2 weeks prior hospitalization addressed drinking problems significantly better. However, the large-scale random trial study MATCH, aim at alcoholics, found no significant differences in drinking behavior between those in the less intensive treatment modality and those in the more intensive ones [9]. In a sample of residential treatment also for alcoholics Moos et al. [48] found that treatment intensity alone explained 1.4-2.9\% of the variance in outcomes. Interestingly, they also found that treatment intensity was explained mainly by a program dummy variable, and that neither patients' consumption level at admission nor social demographic variables were highly associated with it. Although they did not conduct a formal test, this program idiosyncrasy constitutes evidence (but not proof) of the exogeneity of treatment intensity in their study. It is possible that the absence of a significant impact of intensity in the MATCH study was driven, as their critics point out, by the rather strict selection of patients for the study.

As the need to study the active ingredients of programs became more acute, researchers devoted themselves to collecting detailed data on all aspects of the treatment scenario (e.g., location, facility, staff, director, funding, staff enthusiasm and opinion about the program, treatment philosophy). The studies reviewed here generally concluded that substantial differences may follow from small details. For example, Ball and Ross' [7] exhaustive study of six methadone treatment programs reported that leadership, organization, staffing patterns, and amount of services to patients were among the variables that accounted for a significant proportion of the outcome variance between programs. Joe et al. [29] found evidence that patient relapse rates at follow-up were related to both the admission staff and the staff responsible for the treatment plan: More specifically, they found psychiatrists and psychologists were associated with lower relapse rates, and physicians with higher rates. This suggests that treatment quality may depend on staff specialty. Moos, Finney and Cronkite (1990) obtain subjective indicators of quality of treatment from patients and staff. Their questionnaire (COPES) collects data on variables such as support, relationship between staff and patients, organization of the program, etc. One interesting finding is the idiosyncratic nature of these indicators, wich were neither related to quantity/intensity of treatment, nor to the staff's background, nor to the usual indicators such as staff-patient ratio. The study by Moos, Finney and Cronkite (1990) offers, therefore, a very useful additional source of information regarding the active ingredients of treatment in the substance abuse field.

The state-of-the-art research on the benefits of matching treatment to patient characteristics should also be noted (e.g., $[3,9]$ ). Issue 1, volume 94, of Addiction is largely dedicated to the MATCH project, the first project in which alcohol abusers were randomly assigned to three different outpatient interventions to compare differences not only between interventions but also between interventions resulting from particular patient characteristics. MATCH analyzed differences in treatment response for ten such interaction or matching patient characteristics and observed that only psychiatric severity and network supportive of drinking were significantly related to outcome. The latter, however, was found significant only at the 3 -year follow-up period while the former lost strength after the first year follow-up [9, 26]. Although these results were largely unexpected and disappointing, there are important lessons to take from the MATCH project and its criticisms.

Finally, some isolated treatment strategies have reported success (e.g., [24, 33, 34]). One strategy is to use medication to treat substance abuse (for a review see [20]). Acamprosate, for example, has proven very effective in preventing relapse in alcoholics (for reviews see $[41,50]$ ). Anoth-

\section{Matilde P. Machado}

\section{Substance abuse treatment, what do we know? An economist's perspective}

\section{Abstract}

The literature on treating substance abuse has dealt basically with four important questions: (a) Is treatment effective? (b) Are all programs equally effective? (c) Why do programs differ in their effectiveness? (d) Which treatments are more cost-effective? This paper reviews the substance abuse treatment literature around these four questions and discusses methodological issues that hinder the interpretation and generalization of results to date. The answer to the first question is a sounding "yes," treatment is effective but not all programs are equally effective. Researchers have moved beyond the "black box" literature that concentrated on patient and program characteristics as explanations for differences in effectiveness and search for the "active" ingredients of treatment. These include, for example, the treatment philosophy of the program's director and staff attitudes towards patients. Cost-effectiveness studies are less common, and their conclusions are mixed. In general, it is probably safe to say that for the majority of patients, outpatient or shorter programs are more cost-effective.

\section{Keywords}

Substance abuse - Alcohol misuse - Survey . Treatment evaluation · Effectiveness 


\begin{tabular}{|c|c|c|c|c|c|}
\hline Reference & Treatment modality & Cost variables & Output measure & Cost evaluation & Conclusion \\
\hline $\begin{array}{l}\text { Ackerberg } \\
\text { et al. [1] }\end{array}$ & $\begin{array}{l}\text { Outpatient drug-free } \\
\text { (alcoholics), nonran- } \\
\text { dom assignment }\end{array}$ & $\begin{array}{l}\text { Financial expected } \\
\text { average unit } \\
\text { (individual, group and } \\
\text { family sessions) costs } \\
\text { per program }\end{array}$ & $\begin{array}{l}\text { Reduction in alcohol use; } \\
\text { treatment duration, } \\
\text { status at discharge }\end{array}$ & $\begin{array}{l}\text { Patient level regression } \\
\text { analysis controlling } \\
\text { for patient and program } \\
\text { characteristics }\end{array}$ & $\begin{array}{l}\text { Possible to improve } \\
\text { cost-effectiveness } \\
\text { by transfer of "best } \\
\text { practices" }\end{array}$ \\
\hline $\begin{array}{l}\text { Barnett } \\
\text { and } \\
\text { Swindle [8] }\end{array}$ & $\begin{array}{l}\text { Inpatient substance } \\
\text { abuse, nonrandom as- } \\
\text { signment }\end{array}$ & $\begin{array}{l}\text { Treatment costs } \\
\text { (excluded staff re- } \\
\text { search and education } \\
\text { costs) }\end{array}$ & $\begin{array}{l}\text { Readmission within } \\
6 \text { months }\end{array}$ & $\begin{array}{l}\text { Patient level regression } \\
\text { analysis on (average } \\
\text { program cost per day), } \\
\text { length of stay }\end{array}$ & $\begin{array}{l}\text { Shorter programs } \\
\text { more cost effective }\end{array}$ \\
\hline $\begin{array}{l}\text { Fleming } \\
\text { et al. [16] }\end{array}$ & $\begin{array}{l}\text { BI compared to } \\
\text { control group } \\
\text { (alcoholics), } \\
\text { randomized } \\
\text { assignment }\end{array}$ & $\begin{array}{l}\text { Personnel, supplies, } \\
\text { and equipment costs } \\
\text { (clinic) and lost wages } \\
\text { and transportation } \\
\text { (patient) }\end{array}$ & $\begin{array}{l}\text { Several (e.g., change in } \\
\text { alcohol use, health care } \\
\text { use (emergency room and } \\
\text { hospital days), change } \\
\text { in alcohol related events } \\
\text { (e.g., legal events and } \\
\text { motor vehicle accidents) at } \\
6 \text { months and } 12 \text { months } \\
\text { follow-up }\end{array}$ & $\begin{array}{l}\text { Economic analysis of costs } \\
\text { implemented; to establish } \\
\text { the patient opportunity } \\
\text { costs, waiting times, } \\
\text { transportation time and } \\
\text { costs to the clinic, and } \\
\text { time spent with the } \\
\text { physician all multiplied } \\
\text { by an average hourly wage } \\
\text { by occupation; hospital } \\
\text { care computed from } \\
\text { the average Medicare } \\
\text { reimbursement rates which } \\
\text { reflect opportunity costs } \\
\text { better than hospital charges; } \\
\text { costs of crime, accidents and } \\
\text { the legal system taking from } \\
\text { a previous study }\end{array}$ & $\begin{array}{l}\text { Bl was cost-beneficial } \\
\text { for both patients } \\
\text { and the health care } \\
\text { system }\end{array}$ \\
\hline $\begin{array}{l}\text { Holder } \\
\text { et al. [26] }\end{array}$ & $\begin{array}{l}\text { Three outpatient } \\
\text { modalities } \\
\text { (alcoholics), random } \\
\text { assignment }\end{array}$ & $\begin{array}{l}\text { Treatment costs and } \\
\text { inpatient and outpa- } \\
\text { tient medical care } \\
\text { charges over } 3 \text { years } \\
\text { after treatment }\end{array}$ & $\begin{array}{l}\text { Compares treatment } \\
\text { with no treatment over } \\
3 \text { years posttreatment }\end{array}$ & $\begin{array}{l}\text { Estimated per session aver- } \\
\text { age treatment cost (included } \\
\text { therapy, reading materials, } \\
\text { assessment procedures } \\
\text { and laboratory costs); this } \\
\text { estimate multiplied by each } \\
\text { patient's number of sessions; } \\
\text { regression analyses to esti- } \\
\text { mated patient level hospi- } \\
\text { tal/providers charges in the } \\
3 \text { follow-up period }\end{array}$ & $\begin{array}{l}\text { Matching patients } \\
\text { to treatment } \\
\text { associated with } \\
\text { cost-saving effects }\end{array}$ \\
\hline $\begin{array}{l}\text { Long et al. } \\
\text { [31] }\end{array}$ & $\begin{array}{l}\text { Inpatient and outpa- } \\
\text { tient (alcoholics), non- } \\
\text { random assignment }\end{array}$ & $\begin{array}{l}\text { Treatment costs (they } \\
\text { claim all inclusive but } \\
\text { it is not clear how) + } \\
\text { cost of follow-up treat- } \\
\text { ment }\end{array}$ & $\begin{array}{l}\text { Drinking measures at } 6 \\
\text { and } 12 \text { months' follow-up } \\
\text { checked by blood tests }\end{array}$ & $\begin{array}{l}\text { number of days inpatient } \times \\
\text { average charge for inpatient } \\
+ \text { number of days outpatient } \\
\times \text { average charge for } \\
\text { outpatient }\end{array}$ & $\begin{array}{l}2 \text { weeks in }+ \text { day } \\
\text { patient regime was } \\
\text { more cost-effective } \\
\text { than } 5 \text { weeks in } \\
\text { program }\end{array}$ \\
\hline $\begin{array}{l}\text { Longa- } \\
\text { baugh } \\
\text { et al. [32] }\end{array}$ & $\begin{array}{l}\text { Inpatient vs. partial } \\
\text { inpatient (alcoholics), } \\
\text { random assignment }\end{array}$ & $\begin{array}{l}\text { Treatment costs= } \\
\text { hospital charges } \\
\text { including } 6 \text { months } \\
\text { follow-up }\end{array}$ & $\begin{array}{l}\text { Several measures of drink- } \\
\text { ing behavior, life tasks, } \\
\text { readmission } \\
\text { rates at } 6 \text { month after } \\
\text { treatment }\end{array}$ & $\begin{array}{l}\text { Bills from (same) hospital } \\
\text { for each patient including } \\
6 \text { months follow-up }\end{array}$ & $\begin{array}{l}\text { The partial setting is } \\
\text { at least as effective } \\
\text { and less costly than } \\
\text { the inpatient setting }\end{array}$ \\
\hline $\begin{array}{l}\text { Machado } \\
\text { [37] }\end{array}$ & $\begin{array}{l}\text { Outpatient drug-free } \\
\text { (substance abusers), } \\
\text { nonrandom assign- } \\
\text { ment }\end{array}$ & $\begin{array}{l}\text { Financial expected } \\
\text { average program costs } \\
\text { per patient (also cor- } \\
\text { rected by average time } \\
\text { in treatment) }\end{array}$ & Abstinence & $\begin{array}{l}\text { Marginal effect (controlling } \\
\text { for average patient and pro- } \\
\text { gram characteristics) of addi- } \\
\text { tional funds }\end{array}$ & $\begin{array}{l}\text { Possible to reduce } \\
\text { costs while keeping } \\
\text { the abstinence rate } \\
\text { constant }\end{array}$ \\
\hline
\end{tabular}


Table 1 (continued)

Summary of the information of the cost-effectiveness studies

$\begin{array}{llll}\text { Reference } & \text { Treatment modality } & \text { Cost variables } & \text { Output measure } \\ \text { Palmer } & \text { Counseling with } & \text { Simulated long-term } & \text { Simulated long-term } \\ \text { et al. [51] } & \text { acamprosate vs. } & \text { direct medical costs } & \text { outcomes (disease model } \\ & \text { counseling alone } & \text { (disease model) } & \begin{array}{l}\text { calibrated with probabil- } \\ \text { (alcoholics) }\end{array} \\ & & & \begin{array}{l}\text { ities of alcohol-related } \\ \text { diseases from the existing }\end{array} \\ & & & \text { literature) }\end{array}$

Cost evaluation

Incremental costs effective-

ness of total medical costs

with and without acam-

prosate relative to year of life

gained. Costs were based on

national German statistics

for each intervention and

complication

\begin{tabular}{|c|c|c|}
\hline $\begin{array}{l}\text { Schädlich } \\
\text { and Brecht } \\
\text { [52] }\end{array}$ & $\begin{array}{l}\text { Counseling with } \\
\text { acamprosate vs. } \\
\text { counseling alone } \\
\text { (alcoholics), random- } \\
\text { ized assignment }\end{array}$ & $\begin{array}{l}\text { Long-term medical } \\
\text { costs of inpatient } \\
\text { and rehabilitation } \\
\text { treatment }\end{array}$ \\
\hline
\end{tabular}

$\begin{array}{ll}\begin{array}{ll}\text { Shakeshaft } \\ \text { et al. [53] }\end{array} & \begin{array}{l}\text { Bl compared to } \\ \text { cognitive behavior } \\ \text { therapy (alcoholics), } \\ \text { randomized } \\ \text { assignment }\end{array}\end{array}$

Walsh et al. Inpatient and Costs of inpatient

[60] outpatient (alcoholics), treatment over 2 years random assignment from entry

Salaries, training,
and resources mate-
rials (common costs
such as electricity and
rent excluded or
divided equally)
Costs of inpatient
treatment over 2 years
from entry

\section{Abstinence after 48 weeks follow-up and other} predicted alcohol-related medical conditions needing treatment over lifetime (disease model)

\section{Effectiveness index con-} structed ad hoc from

5 drinking indices

\section{2 job performance}

variables; 12 drinking

or drug use variables; during 2 years from entry into program

\begin{tabular}{|c|c|}
\hline $\begin{array}{l}\text { Weisner } \\
\text { et al. [62] }\end{array}$ & $\begin{array}{l}\text { Day hospital vs. } \\
\text { traditional outpatient } \\
\text { (substance and } \\
\text { alcohol abusers), } \\
\text { random assignment } \\
\text { and a "self-selected" } \\
\text { group }\end{array}$ \\
\hline
\end{tabular}

Treatment costs (relative costs were assigned to each activity pool based on staff time within each pool; overhead costs also included via stepdown method)

\section{Drug and alcohol absti-} nence in previous month (self-report checked by urine analysis and breath analysis) at 8 months after intake. ASI alcohol and drug severity scores

\begin{tabular}{|lll|} 
& & \\
\hline $\begin{array}{l}\text { Wutzke } \\
\text { et al. [63] }\end{array}$ & $\begin{array}{l}\text { BI (alcoholics), } \\
\text { random assignment to } \\
\text { three service delivery } \\
\text { strategies }\end{array}$ & $\begin{array}{l}\text { Treatment costs } \\
\text { (marketing, training } \\
\text { and support, physician } \\
\text { time) }\end{array}$
\end{tabular}

Extrapolation of
number of life years saved
nationally by preventing
alcohol-related deaths

\section{Average case related}

treatment and rehabilitation

costs from National German

data

Acamprosate brings

net savings from the

German Health Ser-

vice point of view

\section{Conclusion}

Acamprosate brings net savings from the German Health Service point of view 
the latter did significantly better at reducing drinking. Weisner et al. [62] provide interesting new evidence in a study conducted in the setting of an health maintenance organization. The authors compared two outpatient treatments differing in intensity: a day-hospital modality (compared to inpatient treatment in intensity) and a traditional outpatient modality. They found that although the day-hospital treatment results were not significantly better overall than those in the traditional outpatient setting, the former offered significantly better results in patients with middle-level psychiatric severity and was also more cost-effective. On the other hand, Long et al. [31] compared a 5-week inpatient program with an outpatient program including 2 weeks' residential treatment and concluded that while the differences in outcome at 6 and 12 months were not significant, the revised shorter program was $33 \%$ less expensive. ${ }^{6}$ Similarly, Longabaugh et al. [32] show that the charges of a partial hospital setting are significantly less in a sample of fairly stable patients ( $\$ 1,658$ less on average) than those of an extended inpatient treatment setting, while there are no differences in posttreatment drinking, social functioning, or rehospitalization charges, and attendance at aftercare outpatient services. The review by Holder et al. [25] of 33 submodalities for alcohol treatment conveys a very strong message: cheaper treatment is also usually better treatment.

Some studies have concentrated on a single modality. Machado [37] studied a sample of all publicly funded outpatient treatment programs in Maine for which the Office of Substance Abuse (OSA) collected standardized data on costs, outcomes, and patient and program characteristics. Interestingly, the data show a nonincreasing relationship between costs per patient and outcomes, which may be due to endogeneity of funds per patient. The endogeneity of funds per patient would occur if the Maine OSA allocated more funds per patient to those programs that treat mo-

\footnotetext{
${ }^{6}$ The authors acknowledge that patients were not randomized; furthermore, they note the possible unintended effects that the change in program within the same facility may have had, for instance, on staff and/or patient mood.
}

re difficult patients. The estimated impact of a marginal dollar on the abstinence rate of the representative program controlling for the endogeneity of funds per patient was found to be very small and not statistically significantly different from zero. This result suggests that the OSA could have reduced its budget for substance abuse treatment without compromising abstinence in Maine. Ackerberg et al. [1] used a patient-level dataset similar to that in the Machado study and reached similar conclusions, identifying the least cost-effective programs in Maine. The authors also simulate a number of "transfers" of best practices between programs that would reduce costs by at least $9.2 \%$ without worsening patients' outcomes. The finding that programs differ in effectiveness and costeffectiveness is consistent with previous literature [25]. Holder et al. [26] compared the cost-effectiveness of the three different modalities offered in the MATCH project and found that total medical costs for the least intensive four-session motivational enhancement therapy were lower than the total medical costs of the alternatives (12-session cognitive behavior therapy and 12-step facilitation) over a 3 year follow-up period for which the MATCH team had found no significant differences on drinking outcomes.?

Barnett and Swindle [8] studied only inpatient substance abuse treatment programs. ${ }^{8}$ They used readmission rates within 6 months as the outcome measure. (The authors acknowledge the shortcoming of being able to control only for readmissions into Veterans Affairs hospitals.)

\begin{abstract}
${ }^{7}$ The superior results of motivational enhancement therapy do not hold for the severely ill psychiatric patients or for patients with highly supportive network of drinking, where cognitive behavior therapy was the most cost-effective [26]. Critics of the MATCH project would probably argue that the differences in total medical costs are not really differences in cost-effectiveness but represent either differences in alternative outcome measures that the MATCH team did not care to record or is a result of patient selection in the study. For a review of some criticisms directed at the project MATCH design and methodology see [9].
\end{abstract}

\footnotetext{
${ }^{8}$ Although inpatient treatment programs are less common, they still account for half the funds spent in substance abuse treatment in the United States [8]
}

They conclude that shorter (21-day) inpatient treatment programs are more costeffective than longer (28-day) inpatient treatment programs, and that larger programs are more cost-effective than smaller programs, although the consolidation of small programs, they caution, may restrict access to treatment.

Cost-effectiveness of BI has been examined by very different approaches in numerous studies $[16,53,63]$. Wutzke et al. [63] carried out an extrapolation exercise of cost-effectiveness of BI using the results on effectiveness derived from the multinational World Health Organization study on Identification and Management of Alcohol-Related Problems in Primary Health Care (for references on the WHO report see [63]). They use "the number of life years saved" as outcome measure and extrapolate the costs and benefits of nationwide implementation of the BI program. They conclude that the marginal cost of a year saved is less than 1,873 Australian dollars, a small number by any counts, which most likely will have an impact in stimulating the implementation of these type of programs. ${ }^{9}$ Shakeshaft et al. [53] compared the cost-effectiveness of BI with the more traditional cognitive behavioral therapy. In spite of the limitations of their study, such as a high attrition rate, they were confident of their conclusion that $\mathrm{BI}$ is statistically significantly more cost-effective than cognitive behavioral therapy, at least for those with a low level of alcohol dependence. Fleming et al. [16] performed a cost-benefit analysis of BI (all benefits were translated into monetary units with the exception of the reduction in alcohol use); although the authors have the data for a cost-effectiveness analysis with respect to drinking outcomes, they did not carry it out. This study is included here because it is one of the studies that make a serious effort to evaluate the opportunity

\footnotetext{
${ }^{9}$ Unlike other studies on the effectiveness of $\mathrm{BI}$, the WHO study is probably free of sample selection because (a) it compared types of $\mathrm{BI}$ only with "doing nothing" and not with other programs, and (b) patients were classified according to their drinking abuse severity, and results were obtained for "hazardous" and "harmful" drinking patients separately, where the "hazardous" and "harmful" classifications were obtained from a standardized screening test.
} 
cost of treatment from the societal point of view. Their study uses several outcome measures, from alcohol use to healthcare use and alcohol-related events (e.g., crime and accidents). Their sample does not include very heavy drinkers. They include direct measures of treatment and medical costs as well as measures of lost wages and transportation costs. They conclude that $\mathrm{BI}$ is very cost beneficial.

Finally, Palmer et al. [51] used a disease model to simulate the long-term costs and benefits of alcohol standard therapy with acamprosate relative to standard therapy without acamprosate. In spite of the shortterm costs of medication they found that acamprosate-enhanced therapy is more cost-effective in the long-run since patients enjoy a longer life expectancy with lower life-time costs to the German Health Insurance System. A similar study on the cost-effectiveness of acamprosate was carried out by Schädlich and Brecht [52], also using data from the German Health System. Table 1 summarizes the information on the cost-effectiveness studies discussed in this section.

It is likely that the next decade will see a great increase in cost-effectiveness studies. An important factor in this, of course, is the standardization of data on costs. French and McGeary [18], and the references therein, describe a data collection method that allows the computation of the opportunity costs of substance abuse treatment programs.

\section{Methodological issues of outcome assessment studies}

Some of the methodological issues that have limited the homogenization and comparison of results between studies result from beliefs or preferences (e.g., the choice of output) while others may be the cause of biased results (e.g., self-reported data or timing of measurement). Methodological problems with outcome assessment affect both effectiveness and cost-effectiveness studies.

\section{Outcome measure(s)}

One of the main methodological issues that limit the ability of the literature to provide definite answers to the four ques- tions raised in the "Introduction" is the researchers' choice of outcome measures used to evaluate the effectiveness and costeffectiveness of substance abuse treatment programs. Within the three objectives proposed by McLellan et al. [45] (see above) there are still a wide range of possibilities. Recent years have seen the redefinition of substance abuse treatment as a multiproduct activity. Accordingly, the Addiction Severity Index (ASI) proposed by McLellan et al. [42] has been widely used in recent research. The ASI comprises seven areas: employment, medical status, alcohol use, drug use, legal status, family and social relationships, and psychiatric symptoms. Several alternative sets of outcome indicators have also been used. Two examples are the Maine Addiction Treatment System (MATS) implemented by the Maine OSA $[11,12]$ and the outcome measures used by Moos et al. [48]. MATS was designed to determine multiple outcomes at the patient level (e.g., abstinence, reduction in use, employability, job improvement, problems at job/school, problems with significant other/family, problems with the law and judicial system) to inform the state agency about each program's performance. The intention to make funding conditional on performance was a novelty in the financing of substance abuse treatment programs at the state level. Moos et al. [48] offer a similar set of indicators in the following areas: alcohol consumption, abstinence, physical symptoms, depression, social functioning, and occupational functioning. The interrelationship between the various areas used to evaluate substance abuse treatment performance is still not well understood in the literature. While Jaffe [28] (as cited by Apsler and Harding [6]) found them to be independent in the short run, Moos et al. [48] reported that improvement in one of their six outcomes was associated with improvement in all others.

Although abstinence and reduction in use are considered by most researchers the most important outcome variables (e.g., $[36,37]$, the MATCH project ${ }^{10}$ ). Others, however, have used altervative out-

${ }^{10}$ The "harm-reduction" movement in some European countries is an exception to this belief, aimed mainly at decreasing the devastating consequences of substance abuse, see [40]. put measures such as treatment duration (e.g., [5]), relapse rates $[8,35]$, and even labor market outcomes at 1 year follow-up [19]. Moreover precisely because different outcome variables contain different information regarding patients' overall health status, some authors consider it to be important to integrate several outcome measures in their analysis. Ackerberg et al. [1], for example, combines several outcome variables to measure different aspects of treatment performance. Using data from MATS the authors explore reduction in alcohol use as well as "status at discharge" (i.e., completion of treatment, dropout) and "treatment duration." Choosing an outcome measure is a matter of taste or belief. There is no unique way of measuring effectiveness. While the variety of output measures complicates the comparison between studies, it has certainly enriched our knowledge about the impact of treatment.

\section{Dropouts}

How to deal with treatment dropouts is also not standardized in the literature. While Ackerberg et al. [1] used discharge status (completion of treatment/dropout) as one of the outcome measures, Apsler [5] points out that it is not clear whether dropouts should be included in cost-effectiveness studies. He argues that since these patients have not been subject to "enough" treatment for treatment to be cost-effective, including them penalizes those programs that devote reasonable resources to dropouts. On the other hand, Ball and Ross [7] in their evaluation of methadone programs note that "treatment cannot be considered effective if a patient leaves shortly after admission or is asked to leave because of no-compliance." The statistical treatment of dropouts in evaluations of substance abuse treatment programs is not a marginal issue. There is a widespread perception that dropout rates are high in substance abuse treatment with the exception of methadone programs $[4,6,7,21]$. A related issue is what affects the decision to leave treatment prematurely. This has not been thoroughly studied. Ackerberg et al. [1] modeled the dropout decision as a constant hazard rate that depends on patient characteristics and program dummy vari- 


\begin{tabular}{|c|c|}
\hline $\begin{array}{l}\text { Multiple output } \\
\text { measures }\end{array}$ & $\begin{array}{l}\text { Multiple output measures should be considered. The literature has produced several indexes that summarize } \\
\text { the information of several outcome measures. These typically include drinking/drug abusive behavior, social/family/ } \\
\text { job problems, problems with the law, and psychiatric functioning. }\end{array}$ \\
\hline $\begin{array}{l}\text { How to deal with } \\
\text { dropouts }\end{array}$ & $\begin{array}{l}\text { No definite answer from the existing literature. Some authors claim that dropouts should be counted in the evaluation } \\
\text { some argue the opposite. }\end{array}$ \\
\hline $\begin{array}{l}\text { Clinical trials vs. } \\
\text { field studies }\end{array}$ & $\begin{array}{l}\text { Clinical trials can establish causality effects while field studies cannot. However, the former, are often subject to patient } \\
\text { selection or inability to avoid the control group from receiving additional treatment, which affects the generalization } \\
\text { of results. }\end{array}$ \\
\hline Self-reported data & The accuracy of self-reported data has not been definitely established. There are conflicting studies on this issue. \\
\hline $\begin{array}{l}\text { Timing of } \\
\text { measurement }\end{array}$ & $\begin{array}{l}\text { When to measure a patient substance abuse problem at admission and at discharge is not definitely established } \\
\text { although there are common practices. If measurement is too close to treatment admission, the "hit bottom" effect } \\
\text { may overestimate the substance abuse problem, and if too close to discharge it is not possible to check whether } \\
\text { treatment effects are long term. On the other hand, longer follow-up periods may hurt the identification of the } \\
\text { treatment effects due to confounding factors. }\end{array}$ \\
\hline
\end{tabular}

ables and found that this parsimonious model fits the data relatively well. Age, female gender, white race, low severity, higher income, drunk driving, and probation/ parole emerged as good predictors of treatment retention.

\section{Clinical trials vs. field studies}

There is a rich literature on both clinical trials and field studies. The greatest advantage of random clinical trials is of course their internal validity, that is, the possibility of establishing causality and isolating a particular effect. On the other hand, several authors note the limitations of studies based on this approach (e.g., $[23,57])$. Following Heckman and Smith [23], the difficulty of prohibiting the control group from receiving outside treatment is one of the major problems of clinical trials. Others as Strohmetz et al. [57] (as cited by Finney et al. [15]) offer evidence to the sample selection involved in the voluntary assignment to a study based on clinical trials. More specifically, patients who accept random assignment tend to be more impaired and to have fewer social resources (similar evidence is given by Weisner et al. [62]). On the other hand, others argue that the inclusion/exclusion criteria to be eligible to a clinical trial study results in sample selection since the most severe patients are rejected. The strict selection of patients in randomized clinical trials was, according to critics of the project MATCH, one of the main reasons for the disappointing results obtained [9]. Another example of evidence of sample selection in experimental studies is the review by Finney et al. [15]. They show that when inpatient treatment is found superior to outpatient, it is more likely that the study was based on a naturalistic (without preselection of patients) rather than an experimental design (with preselection). Furthermore, it has also been observed that while dropout rates vary between treatment groups in field studies, they tend to be very similar in experimental studies.

\section{Self-reported data}

Many studies in the literature use self-reported data rather than urine samples or other objective measures of substance use (blood tests and breath analysis). The MATS data, based on interviews to patients at admission and discharge from treatment, fueled substantial research on Maine's substance abuse financing system and on substance abuse treatment effectiveness (e.g., $[1,35,36,37,54])$. MATS thus relies on self-reported measures although filtered by the interviewer clinician, which presumably increases its reliability. ${ }^{11}$ Safeguards to guarantee the accuracy of the data, such as independence

${ }^{11} \mathrm{Lu}$ [35] reported evidence that after the introduction of performance-based contracting between the Maine OSA and the treatment agencies, agencies changed their reporting practices in order to affect their budgets. of the interviewer [45], were not taken in MATS, perhaps because these safeguards are not feasible to implement in real-life scenarios.

Although there are many examples of self-reported data being considered valid and accurate $[7,22,31,45,47,48]$, others show evidence of underreporting close to the admission time in order to facilitate entry into treatment $([2]$; see $[11,38])$. Some argue that patients enter treatment when they "hit bottom" [6], and therefore even if accurately stated, their measures of consumption would most likely be overstated. (For a more comprehensive study on the reasons of entry to treatment see $[30,61]$.) For populations other than substance abusers there are several cases of misreporting (e.g., [10, 27]). Høyer et al. [27], for example, estimate that the general population (i.e., not exclusively alcohol abusers) reports an alcohol consumption level that is only $38.7 \%$ of actual consumption.

\section{Timing of measurement}

The question of when to measure substance abuse status is also not well established in the scientific community. Measuring substance use at admission time may be biased because of the above "hit bottom" [6]. Measuring substance abuse at discharge may not reflect the longterm effects of treatment [6]. On the other hand, longer follow-up periods may have the problem of confounding the effects of several treatment episodes. $\bullet$ Ta- 


\section{Treatment costs}

- Treatment personnel (counselors, nurses, physicians, social workers, psychologists)

- Administration and office personnel

- Space, furniture, equipment

- All other costs involved in treatment

\section{Patient costs}

- Transportation to and from the clinic

- Lost wages from time spent in treatment, waiting time, transportation time

- Day care costs if children under care

- Communication charges

- If treatment is being compared to no treatment, cost from consequences of no treatment must be included (medical costs, lost wages, disease, risk of accidents, crime and legal costs, risk of death; expenditures with drug/alcohol consumption)
Use salaries to evaluate the time they spent with patients, if several regions involved control for regional wage deflators. When volunteer work is done use best approximation, for example, average salaries in the area by occupation.

Use salaries to evaluate these costs. Allocate costs to patients depending on service utilization or time in treatment.

Use what would cost to replace it, for example, if rental rates are competitive use actual rent if not use typical rental rate for space used in area or region. Use replacement costs of equipment and furniture.

Insurance, research costs, training, laboratory, cleaning, materials, communication costs (e.g., telephone).

Use transportation costs (gas/public transport cost).

Use actual patient wages or proxy for potential wage using regional averages by occupation.

Use market prices.

Use regular tariffs.

Very hard to give a value to the cost of disease and low quality of life. Usually medical expenses are used as a proxy. Medical costs should not be taken from bills information. Medicare payments, which are, in general, less generous are typically closer to true cost. If possible use personnel wages and cost information from the hospital/institution. It is even harder to value costs of crime. These involve time spent in jail, costs with legal system, effect on future wages but also personal costs such as loss of freedom that is hard to value. The other difficulty is how to valuate the risk of death. Lost wages due to premature death are certainly a widely used method, which has obvious limitations. Other studies with other approaches can be used to value life. Finally, expenditures with alcohol can be easily computed from market prices but more difficult may be to gather information on drug prices. The solution is to use surveys of drug users about drug prices in the region.

\section{Society costs}

- If the population in treatment is large, treatment may have economy-wide effects on societies that depend on alcohol/drug production or consumption. The effects can be, for example, unemployment and loss of tax revenues

- If treatment is compared with no treatment "no treatment" costs to the society should be valued. These involve costs of crime, costs with police and judicial system.
Losses due to unemployment and production due to reduced demand from alcohol/ drug may be computed from current wages. Losses on tax revenues can be computes directly. Special care should be taken to avoid double counting of costs.

Costs of crime from the society point of view include victims' costs [medical, pain (usually evaluated from judges' compensations to the victims), destruction of property, legal costs]. Police and judicial system are valuated according to their total costs including wages. Careful should be taken to avoid double counting of costs. ble 2 summarizes the main methodological problems in output assessement.

\section{Methodological issues of cost assessment}

As seen in - Table 1, most cost-effectiveness studies limit their analysis to treatment costs or payments, mainly because of the greater simplicity in data collection. Ideally, however, cost-effectiveness studies should measure the "opportunity cost" of treatment from a societal perspective (for a review of the literature on cost effective- ness of alcohol treatment see [17]). The opportunity cost should include all resources needed to provide treatment and valuate them at their second-best use, i.e., at their market value. The costs to be included can be divided into treatment costs and all other costs involved. In practice, however, it is difficult to measure the opportunity cost of treatment (see above and $\bullet$ Table 3 )

\section{Treatment costs}

Most studies of cost-effectiveness in substance abuse limit themselves to treatment costs (see - Table 1). Most studies determine treatment costs from the program or program organization records, which are easily accessible. Despite its simplicity the-

\footnotetext{
12 Yates [64] describes the basic cost categories to be collected for computing treatment costs. This manual, although very useful for orienting programs regarding how to record costs, restricts the cost-effectiveness analysis to simple methods that are not capable of measuring the impact of patient and program characteristics. In particular, these methods are not able to address the probability of patient selection in calculating their cost-effectiveness ratios.
} 
re are still some methodological problems in the computation of treatment costs..$^{12}$

First, all resources used should be evaluated at their market price, and corrections for inflation and location should be made. This means that all donations (including, for example, space and volunteer work) should count as costs although they are free of charge. Evaluation of all resources used in this way guarantees that the total cost obtained is closer to the opportunity cost of treatment than simple accounting costs [18]. Other costs that are incurred, although not when working directly with patients, should also be counted, for example, case planning meetings among counselors or attendance of workshops or training and telephone calls.

Second, it is usually difficult to allocate common costs (e.g., administrative costs, maintenance, accountants, electricity, security, rent) to specific programs within the same organization. The latter are usually considered as indirect treatment costs (e.g., see [55]).

Third, it is important to compute costs per treatment hour, per visit, or costs per patient in the case of outpatient services and cost per patient or cost per patientday in the case of residential services. The simplest practice and most common use is to divide total treatment costs by the number of patients or use other formulas based on expected number of patients to compute "average costs." This is, of course, wrong since patients receive different treatment intensities. Machado [37] and Ackerberg et al. [1], for example, rely on the only information on costs which is reported by agencies at the program level, which is based on expected number of patients and expected costs. The authors, however, try to obtain a more reliable measure of costs by using regression methods to control for different patient and program characteristics that may account for differences in total cost of treatment (on the problems with the use of standardized costs see also [64]).

Forth, researchers often use hospital bills or insurance companies' claims as a data source for treatment costs. These are not representative of true economic costs. Hospital bills and insurance claims reflect not only treatment costs but also market 
structure conditions, i.e., the capacity to affect price in the market.

Fifth, treatment costs should also include costs incurred during some period after discharge. Holder et al. [26], for example, consider a 3-year follow-up period after MATCH while Palmer et al. [51] consider life-long costs.

Sixth, there may be confounding factors that cause difficulty in analyzing costeffectiveness of a particular program or procedure (Yates [64] defines a few common procedures for substance abuse). This would be the case if a patient receives external services, for example, AA, while in treatment or even if for different types of treatment within the same treatment program, such as individual and group counseling.

Seventh, another approach is to consider marginal costs and marginal outcomes (e.g., $[37,63])$. This approach is relevant because it studies the impact of an additional dollar of expenditure on the outcome measure of choice.

Eigth, cost-effectiveness evaluations are restricted to one outcome measure, which may lead to the wrong policy measures. As Machado [37] warns, it would be important to repeat the analysis for other outcome measures before reducing the funding for substance abuse programs in Maine.

Nineth, drop-outs should be included in cost-effectiveness studies because they consume resources, and it would not be accurate to allocate these resources to patients who remained in treatment [64].

\section{Other costs}

When analyzing cost-effectiveness of treatment programs it is important to establish the alternative to treatment. Some studies compare modalities of treatment or intensities within the same modality, while others compare treatment with no treatment. When comparing treatment with no treatment, the costs involved with no treatment should also be assessed. These may involve higher costs to the judicial system, costs to the individual from drug/alcohol purchase, medical costs, and those entailed by shorter life expectancy, lost wages, crime, and accidents. Treatment costs certainly represent a large proportion of the total costs involved, but there are other costs such as transportation costs from home/work to treatment facility, child care in the case of women/men with children under their care, communication charges (e. g. telephone calls to schedule treatment), waiting time, lost wages $[16,17]$, and perhaps economy-wide consequences especially for those economies that depend heavily on alcohol production/consumption (reduced tax revenues, fewer exports, lower employment; see [39]).

\section{Conclusion}

This study reviews the main questions and issues raised by the substance abuse treatment literature. It is clear that treatment is effective, and that not all programs are equally effective. Moreover, although treatment may work better for patients with certain characteristics, for example, less severe psychiatric problems, the "active" ingredients of treatment seem to be very idiosyncratic to treatment programs. Some studies have revealed that, for example, staff qualifications and their rapport with patients are important ingredients. It is also clear that stable alcoholic patients do well in short inexpensive programs while patients with more serious conditions benefit from additional services and longer treatment.

Much has been learned about substance abuse treatment, but researchers still do not have all the answers. Studies are needed that assess long-run benefits and costs of treatment. Researchers also hope to learn more about the benefits of matching patients to treatment and continue their search for the "active ingredients" of treatment. The search for the most effective treatment will also provide leads about the most cost-effective treatment.

Proponents of incentive schemes, such as conditioning funding on performance, may gather from this review that, perhaps even more than for other health services, the multiproduct aspect of treatment of substance abuse, the potential for patient selection, and the potential for misreporting of data are challenges that need to be dealt with to guarantee the success of such schemes.
Corresponding author

\section{Matilde P. Machado}

Universidad Carlos III de Madrid,

Calle Madrid 126, 28903 Getafe, Spain

e-mail: matide.machado@uc3m.es

\section{Acknowledgements}

This research was carried out in part while I was at the IAE, Barcelona, as a Marie Curie postdoctoral fellow (European Community grant \#ERBFMBICT972472). I also thank the research support from the Merck Foundation. Useful comments came from Daniel A. Ackerberg, Michael H. Riordan, and two anonymous referees. Mercedes Cabañas provided invaluable assistance as a documentalist. This article was supported by an unrestricted educational grant awarded jointly to the Universities Carlos III de Madrid and Pompeu Fabra de Barcelona by The Merk Foundation, the philanthropic arm of Merck Co. Inc., White House Station, New Jersey, USA. The responsibility for all errors and omissions is mine.

Conflict of interest: No information supplied

\section{References}

1. Ackerberg DA, Machado MP, Riordan MH (2001) Benchmarking for productivity improvement: a health care application. International Economic Review, forthcoming

2. Aitken LS (1986) Retrospective self-reports by clients differ from ongoing reports: implications for the evaluation of drug treatment programs. Int J Addict 21:767-788

3. Allen JP, Babor TF, Mattson ME, Kadden RM (2003) Matching alcoholism treatment to client heterogeneity, the genesis of project MATCH. In Babor TF, del Boca FK (eds) Treatment matching in alcoholism. Cambridge University Press: Cambridge

4. Anglin MD, Hser Y (1990) Treatment of drug abuse. In: Tonry M, Wilson JQ (eds) Crime and justice: an annual review of research, vol 13. University of Chicago Press: Chicago

5. Apsler R (1991) Evaluating the cost-effectiveness of drug abuse treatment services. In: Economic costs, cost-effectiveness, financing and communitybased drug treatment. Research monograph series 113. National Institute on Drug Abuse: Rockville, pp $17-26$

6. Apsler R, Harding W (1991) Cost-effectiveness analysis of drug abuse treatment: current status and recommendations for future research. In: Drug abuse services research series. No 1: background papers on drug abuse financing and services research. DHHS publ no (ADM) 91-17777. National Institute on Drug Abuse: Washington, pp 58-81

7. Ball JC, Ross A (1991) The effectiveness of methadone maintenance treatment: patients, programs, services, and outcome. Springer: Berlin Heidelberg New York

8. Barnett PG, Swindle RW (1997) Cost-effectiveness of inpatient substance abuse treatment. Health Serv Res 32:615-629 
9. Brown TG, Wood W-J (2001) Are all substance abuse treatments equally effective? Comité Permanent de Lutte à la Toxicomanie, Deuxiéme trimestre 2001, Gouvernement du Québec, Ministère de la Santé et des Services Sociaux

10. Butler JS, Burkhauser RV, Mitchell J, Pincus TP (1987) Measurement error in self-reported health variables. Rev Econ Stat 69:644-650

11. Commons M, McGuire TG (1997) Some economics of performance based contracting for substance abuse services. In: Egertson JA, Fox DM, Leshner Al (eds) Treating drug abusers effectively. Milbank Memorial Fund and Blackwell Publishers, pp 223-249

12. Commons M, McGuire TG, Riordan MH (1997) Performance contracting for substance abuse treatment. Health Sci Res 32:631-650

13. Drummond DC (1997) What I would most like to know about alcohol interventions: do the best things come in small packages? Addiction 92:375379

14. Emrick CD (1975) A review of psychological oriented treatment for alcoholism. II. The relative effectiveness of different treatment approaches and the effectiveness of treatment versus non-treatment. J Stud Alcohol 36:88-108

15. Finney JW, Hahn AC, Moos RH (1996) The effectiveness of inpatient and outpatient treatment for alcohol abuse: the need to focus on mediators and moderators of setting effects. Addiction 91:1773-1796

16. Fleming MF, Mundt MP, French MT, Manwell LB, Stauffacher EA, Barry KL (2000) Benefit-cost analysis of brief physician advice with problem drinkers in primary care settings. Med Care 38:7-18

17. French MT (2001) Economic evaluation of alcohol treatment services. Recent developments in alcoholism, vol 15. Kluwer/Pelnum, New York pp 209228

18. French MT, McGeary KA (1997) Estimating the economic cost of substance abuse treatment. Health Econ Lett 6:539-544

19. French MT, Zarkin GA, Hubbard RL, Rachal JV (1991) The impact of time in treatment on the employment and earnings of drug abusers. Am J Public Health 81:904-907

20. Garbutt JC, West SL, Carey TS, Lohr KN, Crews FT (1999) Pharmacological treatment of alcohol dependence, a review of the evidence. JAMA 13181325

21. Gerstein DR, Hardwood HJ (eds) (1990) Treating drug problems. Institute of Medicine, National Academy: Washington

22. Grant KA, Arciniega LT, Tonigan JS, Miller WR, Meyers $R$ (1997) Are reconstructed self-reports of drinking reliable? Addiction 92:601-606

23. Heckman JJ, Smith JA (1995) Assessing the case for social experiments. J Econ Perspect 9:85-110

24. Higgins ST, Budney AJ, Bickel WK, Badger GJ (1994) Participation of significant others in outpatient behavioral treatment predicts greater cocaine abstinence. Am J Drug Alcohol Abuse 20:47-56

25. Holder HD, Longabaugh R, Miller WR, Rubonis AV (1991) The cost effectiveness of treatment for alcoholism: a first approach. J Stud Alcohol 52:517540

26. Holder HD, Cisler RA, Longabaugh R, Stout RL, Treno AJ, Zweben A (2000) Alcoholism treatment and medical care costs from project MATCH. Addiction 95:999-1013

27. Høyer G, Nilssen O, Brenn T, Schirmer H (1995) The Svalbard study 1988-89: a unique setting for validation of self-reported alcohol consumption. Addiction 90:539-544 comment on the state of the art. In:Tims FM, Ludford JP (eds) Drug abuse treatment evaluation: strategies, progress and prospects. Research monograph no. 51. National Institute on Drug Abuse: Rockville, pp 13-28

29. Joe GW, Simpson DD, Sells SB (1994) Treatment process and relapse to opiod use during methadone maintenance. Am J Drug Alcohol Abuse 20:173-197

30. Kirchner JE, Booth BM, Owen RR, Lancaster AE, Smith GR (2000) Predictors of patient entry into alcohol treatment after initial diagnosis. J Behav Health Serv Res 27:339-346

31. Long CG, Williams M, Hollin CR (1998) Treating alcohol problems: a study of programme effectiveness and cost-effectiveness according to length and delivery of treatment. Addiction 93:561-571

32. Longabaugh R, McCrady B, Fink E, Stout R, McAuley T, Doyle C, McNeill D (1983) Cost-effectiveness of alcoholism treatment in partial versus inpatient settings - six month outcomes. J Stud Alcohol 44

33. Longabaugh R, Beattie M, Noel N, Stout R, Malloy $P$ (1993) The effect of social investment on treatment outcome. J Stud Alcohol 54:465-478

34. Longabaugh R, Wirtz PW, Zweben A, Stout RL (1998) Network support for drinking, Alcoholics Anonymous and long-term matching effects. Addiction 93:1313-1333

35. Lu M (1999) Separating the "true effect" from "gaming" in incentive based contracts in health care. J Econ Manage Strategy 8:383-431

36. Lu M, McGuire TG (2002) The productivity of outpatient treatment for substance abuse. J Hum Resour 37:339-335

37. Machado MP (2001) Dollars and performance: treating alcohol misuse in Maine. J Health Econ 20:639-666

38. Maitso SA, McKay JR, Connors GJ (1990) Self-report issues in substance abuse: state of the art and future directions. Behav Assess 12:117-134

39. Maynard A, Godfrey C (1994) Alcohol policy-evaluating the options. Br Med Bull 50:221-230

40. Marlatt GA (1996) Harm-reduction: come as you are. Addict Behav 1:779-788

41. Mason BJ (2001) Treatment of alcohol-dependent outpatients with acamprosate: a clinical review. J Clin Psychiatry 62 [Suppl 20]:42-48

42. McLellan AT, Luborsky L, O'Brien CP, Woody GE (1980) An improved evaluation instrument for substance abuse patients: the addiction severity index. J Nerv Ment Dis 168:26-33

43. McLellan AT, Grissom GR, Brill P, Durell J, Metzger DS, O'Brien CP (1993) Private substance abuse treatments: are some programs more effective than others? J Subst Abuse Treat 10:243-254

44. McLellan AT, Arndt IO, Metzger DS, Woody GE, O'Brien CP (1993) The effects of psychosocial services in substance abuse treatment. JAMA 269:1953-1959

45. McLellan AT, Woody GE, Metzger DS, McKay J, Durell J, Alterman Al, O'Brien CP (1997) Evaluating the effectiveness of addiction treatments: reasonable expectations and appropriate comparisons. In: Ergertson JA, Fox DM, Leshner Al (eds) Treating drug abusers effectively. Milbank Memorial Fund and Blackwell Publishers, pp 7-40

46. McLellan TA, Hagan TA, Levine M, Gould F, Meyers K, Bencivengo M, Durell J (1998) Supplemental social services improve outcomes in public addiction treatment. Addiction 93:1489-1499
47. Midanik L (1982) The validity of self-reported alcohol consumption and alcohol problems: a literature review. Br J Addict 77:357-382

48. Moos R, Finney J, Cronkite RC (1990) Alcoholism treatment. Oxford University Press: Oxford

49. Morgnstern J, Longabaugh R (2000) Cognitive-behavioral treatment for alcohol dependence: a review of evidence for its hypothesized mechanisms of action. Addiction 95:1475-1490

50. Overman GP, Teter CJ, Guthrie SK (2003) Acamprosate for the adjunctive treatment of alcohol dependence. Ann Pharmacother 37:1090-1099

51. Palmer AJ, Neeser K, Weiss C, Brandt A, Comte S, Fox M (2000) The long-term cost-effectiveness of improving alcohol abstinence with adjuvant acamprosate. Alcohol Alcohol 35: 478-492

52. Schädlich PK, Brecht JG (1998) The cost effectiveness of acamprosate in the treatment of alcoholism in Germany. Economic evaluation of the Prevention of Relapse with Acamprosate in the Management of Alcoholism (PRAMA) study. Pharmaecoconomics 13:719-730

53. Shakeshaft AP, Bowman JA, Burrows S, Doran CM, Sanson-Fisher RW (2002) Community-based alcohol counseling: a randomized clinical trial. Addiction 97:1449-1463

54. Shen Y (2003) Selection incentives in contracting. Health Serv Res 38:535-553

55. Shepard DS et al. (2003) The ADSS cost study: costs of substance abuse treatment in the specialty sector. United States Department of Health and Human Services, Substance Abuse and Mental Health Serv Administration, Office of Applied Studies: Rockville

56. Silverman K, Robles E (1998) Employment as a drug abuse treatment intervention. NBER working paper no 6402

57. Strohmetz DB, Alterman Al, Walter D (1990) Subject selection bias in alcoholics volunteering for a treatment study. Alcohol Clin Exp Res 14:736-738

58. Tims FM, Fletcher BW, Hubbard RL (1991) Treatment outcomes for drug abuse clients. Pickens CG, Leukefeld CG, Schuster CR (eds) NIDA research monograph 106. United States Department of Health and Human Services: Rockville

59. Trent LK (1998) Evaluation of a four- versus sixweek length of stay in the Navy's alcohol treatment program. J Stud Alcohol 59:270-279

60. Walsh DC, Hingson R, Merrigan D, Levenson SM, Cupples A, Heeren T, Coffman G, Becker C, Barker T, Hamilton S, McGuire TG, Kelly C (1991) A randomized trial of treatment options for alcohol-abusing workers. N Engl J Med 325:775-782

61. Weisner C, Matzger H (2002) A prospective study of the factors influencing entry to alcohol and drug treatment. J Behav Health Serv Res 29:126137

62. Weisner C, Mertens J, Parthasarathy S, Moore C, Hunkeler EM, Hu T, Selby JV (2000) The outcome and cost of alcohol and drug treatment in an HMO: day hospital versus traditional outpatient regimens. Health Serv Res 35:791-812

63. Wutzke SE, Shiell A, Gomel MK, Conigrave KM (2001) Cost-effectiveness of brief interventions for reducing alcohol consumption. Soc Sci Med 52:863-870

64. Yates BT (1999) Measuring and improving costs, cost-effectiveness and cost-benefit for substance abuse treatment programs. National Institute on Drug Abuse, NIH publ no 99-4518. United States Department of Health and Human Services: Rockvilledomize patients into treatment alternatives and the sample was composed of rather stable individuals. 